\title{
Sistema de Parques e Corredores Verdes de Raleigh, Carolina do Norte, EUA: um Parque com a cidade dentro
}

\author{
Sistema de Parques y Corredores Verdes de Raleigh, Carolina \\ del Norte, EE. UU: un Parque con la ciudad dentro
}

\section{Raleigh Parks and Green Corridors System, North Carolina, USA: A Park with the city within}

\author{
Luis Guilherme Aita Pippi \\ guiamy@hotmail.com \\ Universidade Federal de Santa Maria, UFSM, Santa Maria, RS
}

Fabio Angeoletto

fabio_angeoletto@yahoo.es

Universidade Federal de Mato Grosso, UFMT, campus de Rondonópolis, MT

\begin{abstract}
Resumo: Esse trabalho se propõe a analisar a eficácia do Plano para a Cidade Média de Raleigh, Carolina do Norte, EUA através de seu planejamento e projeto de um sistema de Parques e de Corredores Verdes, como um exemplo a ser seguido pelas cidades contemporâneas, no que tange ao planejamento e conectividade de seu sistema de espaços livres, representado por parques, áreas recreativas e corredores verdes. Nesse sentido, a qualidade de vida urbana de seus habitantes, dos espaços livres, e perpetuidade dos recursos naturais da cidade de Raleigh está diretamente relacionada com a oportunidade da efetivação do primeiro plano americano da rede de corredores verdes para uma capital, "Um Parque com uma Cidade dentro", como forma a conter o crescimento urbano, minimizar os impactos antrópicos e promover o incremento de áreas de lazer e recreação em todas as áreas da cidade, bem como a sua conectividade e funcionalidade dos mesmos. A eficácia da constituição desse sistema integrado, constituído pela rede de corredores verdes está baseada pela efetivação e constituição do plano como um todo, no transcorrer de diversos períodos, onde através do esboço de suas características, objetivos e funções pretende-se lançar bases sólidas para discussões, premissas e estratégias para o planejamento, projeto renovação das estruturas existentes do sistema de parques e corredores verdes.
\end{abstract}

Palavras-chave: ecologia urbana; conectividade áreas verdes; cidades médias norte americanas; planejamento ambiental.

Resumen: Este trabajo se propone analizar la eficacia del Plan para la ciudad media de Raleigh, Carolina del Norte, EE.UU. a través de su planificación y diseño de un sistema de Parques y de Corredores Verdes, como un ejemplo a seguir por las ciudades contemporáneas, en lo que se refiere a la planificación y conectividad de su sistema de espacios libres, representado por parques, áreas recreativas y corredores verdes. En este sentido, la calidad de vida urbana de sus habitantes, de los espacios libres, y perpetuidad de los recursos naturales de la ciudad de Raleigh está directamente relacionada con la oportunidad de la efectividad del primer plano americano de la red de corredores verdes hacia una capital, "Un Parque con una ciudad dentro ", 
como forma de contener el crecimiento urbano, minimizar los impactos antrópicos y promover el incremento de áreas de ocio y recreación en todas las áreas de la ciudad, así como su conectividad y funcionalidad de los mismos. La eficacia de la constitución de este sistema integrado, constituido por la red de corredores verdes está basada en la efectividad y constitución del plan como un todo, en el transcurso de diversos períodos, donde a través del bosquejo de sus características, objetivos y funciones se pretende sentar bases sólidas para discusiones, premisas y estrategias para la planificación, proyecto de renovación de las estructuras existentes del sistema de parques y corredores verdes.

Palabras clave: ecología urbana; conectividad de áreas verdes; ciudades medias de Norteamérica.; planificación ambiental.

\begin{abstract}
This paper proposes to analyse the effectiveness of the Plan for the mediumsized city of Raleigh, North Carolina, USA through its planning and design of a system of Parks and Green Corridors as an example to be followed by contemporary cities, in relation to the planning and connectivity of its open space system, represented by parks, recreational areas and green corridors. In this sense, the quality of urban life of its inhabitants, free spaces, and perpetuity of the natural resources of the city of Raleigh is directly related to the opportunity of the realization of the first American plan of the network of green corridors to a capital, "A Park with a City within ", as a way to contain urban growth, minimize anthropic impacts and promote the increase of leisure and recreation areas in all areas of the city, as well as their connectivity and functionality. The effectiveness of the constitution of this integrated system, consisting of the network of green corridors, is based on the implementation and constitution of the whole plan, over a period of several years, through the outline of its characteristics, objectives, and functions. Discussions, premises, and strategies for planning, project renovation of existing structures of the park system and green corridors.
\end{abstract}

Keywords: urban ecology; connectivity of green areas; American medium-sized cities; environmental planning

\title{
HISTÓRICO DA CAPITAL AREA DE RALEIGH: CRESCIMENTO URBANO X PLANEJAMENTO URBANO
}

A cidade média de Raleigh, capital do Estado da Carolina do Norte nos Estados Unidos teve seu primeiro Plano Diretor feito por William Christmas em 1792, em uma área de uma milha quadrada, foram resguardados para uso público uma área de 1,62 ha (quatro acres quadrados) - Caswell, Nash, Burke e Moore, legado este que representava o primeiro parque publico da cidade. Em 1887, Stanhope Pullen doou uma área de 69 hectares para a administração publica, para parque público.

Em 1925, cidadãos representantes dos clubes e organizações constituíram a primeira comissão de parques da cidade, encarregados de formular os primeiros planos para o desenvolvimento do sistema de parques. Em 1935 foi estabelecida a primeira comissão de recreação na cidade, que passou a programar diversos programas de lazer e recreação. Nos anos 1950, 1960 e 1970, outros parques foram criados e diversos programas e facilidades foram constituídas numa área de aproximadamente $40 \%$ de um total de 182,10 ha (450 acres. Durante anos a cidade se expandiu para fora desses limites e começou a pressionar as áreas naturais. Nessa fase inicial de desenvolvimento da cidade, as áreas dos recursos 
hídricos composta por rios, riachos e tributários não eram respeitadas e sequer protegidas, e o zoneamento do solo urbano permitia a edificação sobre estas áreas para usos residenciais, industriais e comerciais.

Somente em 1950 áreas significativas com características naturais foram incluídas no zoneamento urbano da cidade. Nessa época foram feitos os primeiros projetos de controle contra inundações, bem como o plano de desenvolvimento do solo urbano onde se promoveria a inserção de corredores públicos circundando os recursos hídricos dentro da cidade, como uma solução parcial para conter os problemas de inundação e ao mesmo tempo promover usos de recreação e conservação dos recursos (FLOURNOY, 1969; ZACHARY et al., 1977).

\section{CONCEITO ESTRUTURADOR DO PLANO DIRETOR DE RALEIGH: UM PARQUE COM UMA CIDADE DENTRO}

Entre período de 1970 e 1980 a cidade de Raleigh foi re-planejada com o intuito de resguardar seus espaços livres dos impactos do crescimento urbano. Em função da presença dos atributos naturais de sua paisagem, iniciou-se a discussão sobre o futuro da cidade e para garantir a integridade ecológica e paisagística foi criado o Sistema de Parques, Áreas de Recreção e Espaços Livres, com o intuito de consolidar um exemplo a ser seguido nos Estados Unidos, através da ideologia "Um Parque com a Cidade Dentro". Segundo Evans (1969) e Flournoy (1969), nessa época a cidade apresentava em abundância remanescentes de espaços livres vegetados e hídricos, cujos atributos paisagísticos poderiam apenas receber usos para fins recreacionistas de intra-vizinhança.

A partir do planejamento da relação entre espaços livres e espaços edificados, surgiu a principal premissa de planejamento da cidade, onde os espaços livres tinham um papel fundamental na nova configuração da cidade, a partir da caracterização dos ambientes naturais. Devido ao solo urbano muito valorizado, inicialmente os recursos ecológicos e paisagísticos só estavam garantidos a particulares, representados por pessoas da sociedade de classe alta. Para reverter o déficit de espaços livres de uso publico, foi criado o Sistema de Rede de Parques, Espaços Livres Verdes e Escolas de Raleigh. Dessa forma criou- se a estrutura do Sistema Lazer e Recreação conformado por Parques e pelo Sistema de Corredores Verdes da cidade, ilustrados na Figura 1 (EVANS, 1969; FLOURNOY, 1969). 
Figura 1: Planejamento de Parques e Corredores Verdes de Raleigh.



Fonte: Evans, 1969.

\section{Plano das Áreas de Lazer e Recreação: Categorias Tipológica de Parques e Corredores Verdes}

O plano de 18 anos (1977-1995): Parque e Recreação proposto para Raleigh, tinha como principal meta garantir a qualidade de vida urbana de todos os cidadãos e ao mesmo tempo garantir a integridade ecológica e paisagística do ambiente natural da cidade, através do desenvolvimento e manutenção de um plano abrangente com atividades de lazer e recreação.

O Plano de 18 anos foi dividido em diversas etapas, que consistiam na aquisição gradual de áreas e desenvolvimento de trilhas para pedestres e ciclistas, bem como manutenção e expansão do perímetro das áreas pré-existentes (ZACHARY et al., 1977).

O Plano de Lazer e Recreação do Sistema de Parques e Corredores Verdes baseou-se nos documentos de projeção demográfica para Raleigh nos períodos de 1979, 1983 e 1995, para então analisar a demanda de parques, serviços e recreação para cada gleba da cidade. $\mathrm{O}$ plano previu para a efetivação das áreas ativas de recreação num custo estimado por 10 anos de US\$ 2 centavos por pessoa/dia e dessa forma a cidade de Raleigh, passou a ter novas áreas de recreação que seriam distribuídas de forma e igualitária (FLOURNOY, 1969; ZACHARY et al., 1977). As áreas e facilidades inventariadas foram categorizadas em:

Parques Especiais, em torno de 1,6 acres /1000 habitantes, na forma de Parques de Bolso (áreas primárias de serviço e atendimento acima de 1/4 milha, somente quando 
necessário, e área menor que um acre); 20 Mini-Parques (área de atendimento e serviço acima de 1/2 milha, com tamanho de 1 a 5 acres);

Parques de Escalas Menores e Parques de Vizinhança (área de atendimento e serviço de 2,5 acres /1000 habitantes de 8 a 12 acres e poucas facilidades);

Parques Comunitários (área de atendimento e serviço de 2,5 acres /1000 habitantes e tamanho de 40 a 75 acres, com moderadas facilidades), com Centros Comunitários incorporados;

Parques com Maiores Escalas, como Parques Metropolitanos (área de atendimento e serviço de 5 acres/1000 habitantes, com tamanho de 120 a 200 acres e diversas facilidades) cada um apresentando uma grande e importante gleba utilizada constantemente pela comunidade e turistas para fins de recreação. Um dos mais representativos, Lake Johnson Park, apresenta facilidades como áreas multiuso, trilhas, áreas para piquenique e contemplação, estacionamento, áreas para pesca, passarelas de madeira, centro de educação ambiental, sanitários, quadras de tenis e piscina pública, além de um grande lago eáreas de banhado, bem como floresta nativa, situado ao norte de Raleigh e interconectado ao projeto hídrico da cidade;

Corredores Verdes - área de atendimento e serviço em torno de 1,1 acre/1000 habitantes;

O plano ainda previu a aquisição de três Parques Regionais: The Falls of the Neuse Lake e a localidade de Wilson Mills Lake, junto a estação de tratamento de agua da cidade, bem como apresentou soluções de projeção populacional para o futuro. Nesse âmbito regional, encontramos maiores facilidades recreacionais, bem como corredores verdes com finalidades mais conservacionista, como por exemplo, áreas como William B. Umstead State Park e Lake Wheeler Park, cujo lagos permitiria acesso publico e recreativo, aliado a conservação ambiental, onde seria proposto passeios náuticos de bote, skiing, pesca, natação e pesquisas científicas e camping (EVANS, 1969).

Ainda no sistema de Parques em Raleigh, foram incorporadas outras áreas públicas vegetadas como praças, campos de golfe, sítios históricos e outros espaços livres privados e comunitários (EVANS, 1969).

\section{Participação Comunitária e Programas de Lazer e Recreação do Sistema de Parques}

Junto ao Sistema de Parques, a cidade foi planejada com facilidades recreativas e áreas destinadas a camping. Dentre as facilidades recreativas constavam quadras de tenis; quadras poliesportivas, campos de futebol, beisebol e golfe; facilidades para práticas náuticas (barcos a vela, caiaques e canoas); anfiteatros. Aliado ao planejamento destas áreas constituiu- se diversos programas de apoio, que atraíram a participação ativa dos cidadãos através de seu envolvimento nas atividades, bem como trabalho voluntário (CITY OF RALEIGH PLANNING WEBSITE, 2010). 


\section{SISTEMA DE CORREDORES VERDES: RALEIGH - CAPITAL AREA DE CORREDORES VERDES}

Conforme Little (1990) o Plano para a Capital Area de Corredores Verdes de Raleigh foi o primeiro plano nos Estados Unidos no âmbito da esfera local, cuja origem deriva do trabalho de tese de mestrado de Bill Flourney(1970), estudante do College of Design da Universidade da Carolina do Norte, que previa a conservação dos recursos e de suas funções no meio urbano, através da conformação de um sistema de 'dedos verdes' numa rede de corredores lineares, que conformaria um sistema integrado, ligando parques, comunidades, escolas, áreas comerciais, shopping centers e outras localidades (FLINK; SEARNS, 1993; FLINK, 2006).

Em 1974, o plano conhecido como Raleigh: um Parque com uma cidade dentro começou a ser desenvolvido por Frank Evans, diretor e coordenador do Departamento de Parques e Recreação da cidade, que estruturou o Sistema de Corredores Verdes de Raleigh baseado nas premissas, e ideias lançadas por Bill Flourney, em como deveriam ser planejados, estruturados e implantados os corredores verdes; como deveriam ser zoneadas as áreas alagáveis da cidade, bem como construídos os caminhos a serem interligados. Com o intuito de garantir a preservação dos mesmos, foi então criado o plano de ação para resguardar a beleza e potencialidade dos atributos naturais e paisagísticos dos corredores verdes dos impactos urbanos. (EVANS, 1969; LITTLE, 1990).

Para a criação do Sistema de Corredores Verdes foi criada em 1974 a primeira Comissão de Corredores Verdes de Raleigh, com 18 representantes, a qual teria suporte administrativo do Departamento e Construção da cidade, e suporte operacional promovido pelo Departamento de Parques. A seguir foram buscados recursos para implantação dos dois projetos pilotos, com aquisição de mais de 100 acres a serem destinados aos corredores verdes, e a execução efetiva dos projetos pilotos (ZACHARY et al., 1977; FLINK; SEARNS, 1993).

Conforme Evans (1969) o plano de ação consistiu em duas importantes etapas: primeiramente foram elencadas as Unidades de Paisagem mais significativas da cidade, que mereciam ser conservadas: trilhas e caminhos conectores de parques, recursos hídricos, vistas cênicas, sítios históricos, áreas alagáveis e topografia. Posteriormente, procurouse valorizar as áreas com as condições ambientais sensíveis aos usos antrópicos, pelo resguardo e proteção dessas áreas prioritárias para perpetuação paisagística: estética, ecológica, morfológica e funcional. Dessa forma, através da implementação de Corredores Verdes foi possibilitada a construção paisagística de trilhas e caminhos, bem como de nós de recreação, com intuito de promover a mobilidade alternativa de pedestres e ciclistas, conexão entre Parques, Escolas, Centros Históricos, Bairros, Áreas Comerciais e outros ambientes da cidade (Fig. 2). 
Figura 2 - Mapa do Sistema Regional de Parques e Corredores Verdes: o triângulo compreende as áreas urbanas de Raleigh, Durhan e Chapelhill, Carolina do Norte.



Fonte: modif. de Flournoy, 1969.

Outro aspecto importantíssimo para eficácia do plano de ação de Corredores Verdes foi promover benefícios sociais, econômicos, ambientais e estéticos, bem como garantir a manutenção dos mesmos e segurança publica dos usuários (ZACHARY et al., 1977; LITTLE, 1990; FLINK; SEARNS, 1993).

Segundo Evans (1969) a concepção do Plano de Corredores Verdes abrangeu diferentes etapas de financiamento e implementação, divididas em três partes: Sistema de Corredores Verdes, rede de trilhas e caminhos e áreas recreação ativa através das diferentes Categorias Tipológicas de Parques. Estes foram reforçados pelas necessidades ambientais e recreacionais, que gerou as políticas de proteção ambiental, dando assim suporte jurídico ao plano.

A implantação do Plano 'Capital Area' de Corredores Verdes exigiu as seguintes metas: aquisição de parcelas de áreas públicas; zoneamento das áreas alagáveis; zoneamento das áreas recreativas; cooperação das áreas de desenvolvimento e planejamento urbano; preservação dos espaços livres privados (clubes privados com redução de taxas e outros mecanismos legislativos). Assim, foram mapeados o Sistema de Espaços Livres Públicos e Privados: Parques (propostos e existentes), Unidades Escolares (existentes e propostas), Facilidades Comunitárias e Rede de Corredores Verdes. Esse zoneamento hierárquico de diferentes Parques e Parques Lineares tinha como intuito garantir o funcionamento das áreas de recreação ativa da cidade de forma harmônica com a preservação ambiental e usos residenciais no presente e futuro. Dessa forma esse Sistema de Parques, através da conectividade de Corredores Verdes, iria interligar as áreas pré-existentes e privilegiadas aos subúrbios da cidade.

A constituição dos Corredores Verdes não teve implementação simples sobre as áreas urbanas consolidadas, devido ao fato das glebas de espaços livres disponíveis serem 
pequenas, além de interesses da especulação imobiliária sobre estar áreas. Por outro lado, nas áreas ainda não ocupadas, vazios urbanos, o conceito e implantação dos corredores verdes foram adotados como forma a amenizar os conflitos urbanos, diminuindo assim a competição e problemas durante a urbanização, e promovendo conexões alternativas para o solo urbano ao mesmo tempo proporcionando estrutura e funções para as áreas de futura expansão da cidade (FLOURNEY, 1969).

Figura 3: Mapa temático atual do Sistema de Parques e Recreação de Raleigh: Capital Area de Corredores Verdes.



Fonte: Raleigh Parks and Recreation, 2019. 
Apos a implantação dos primeiros Corredores Verdes, a comunidade, empreendedores e planejadores perceberam não só os benefícios como a potencialidade dos Corredores Verdes, passando assim a valorizar e resguardar áreas para futuro planejamento e implantação do sistema na cidade. Esse fenômeno modificou a forma de desenvolvimento urbano na cidade, que passou a promover mais áreas de espaços livres com oportunidades e facilidades recreativas e paisagísticas. Conforme Flourney (1969) o envolvimento com a Rede de Parque Lineares, começou a influenciar a direção do padrão de desenvolvimento urbano. Ainda segundo Flourney (1969, p. 15), a Capital Area de Corredores Verdes pode complementar o Sistema de Parques e Recreação (Fig. 3) através da introdução de uma rede de parques lineares em Raleigh, representando assim espaços livres mais acessíveis a toda a população, viabilizar atividades, além de conservar remanescentes de espaços livres, estabilizar a densidade urbana e manter a qualidade de vida urbana da cidade.

\section{CONCEITOS, CARACTERÍSTICAS, FUNÇÕES E ELEMENTOS PROJETUAIS DOS CORREDORES VERDES}

\section{Corredores Verdes}

Conforme Flournoy (1969) e Departamento de Planejamento da Cidade de Raleigh (1979) o conceito de corredores verdes utilizado em Raleigh, teve como origem estratégica, na forma alternativa para conter os problemas de alagamentos da cidade, através da introdução de um sistema interconectado de corredores verdes com espaços livres naturais, limítrofes a diferentes áreas e usos urbanos, com dimensões mínimas variando de 30,48 metros (100 pés) a 121,92 metros (400 pés) em cada lado da margem dos recursos hídricos, variando conforme suas características. Através dessa rede integrada e conectada, onde através das trilhas poderiam se penetrar em diferentes áreas da cidade.

A grande vantagem dos Corredores Verdes sobre outros tipos de espaços livres está em sua composição formal e linear estratégica, onde se consegue percorrer uma grande variedade de áreas da cidade, devido a sua configuração perimetral, de forma a atender a mais serviços urbanos e ambientais, bem como estar mais acessível a um maior número de pessoas. Ao conectar e penetrar através do sistema linear diferentes áreas da cidade (Fig. 4), promove-se assim benefícios a diferentes áreas, bem como promover amenidades visuais em todo seu percurso (FLOURNOY, 1969). 
Figura 4 - Esquema Composição Formal e Funcional de Corredores Verdes.

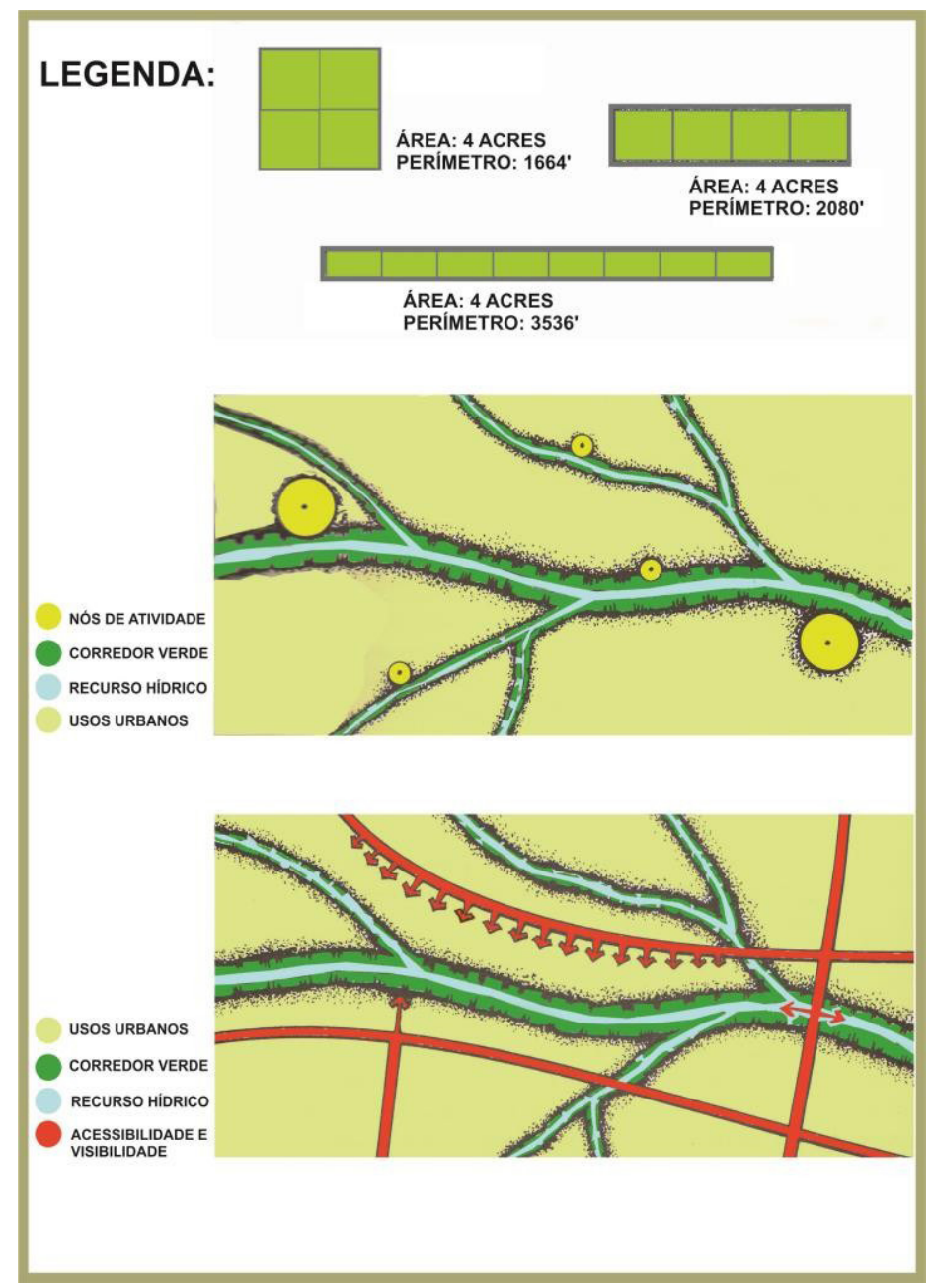

Fonte: mod. de Flournoy, 1969.

Dessa forma constituiu-se uma rede de parques lineares como um sistema conector de trilhas para usos alternativos da mobilidade urbana (pedestres e ciclistas) e mobilidade biótica, bem como interligar diferentes usos e áreas da cidade. Os parques lineares ademais possuem a mesma função dos outros tipos de parque: lazer, recreação, conservação dos recursos e ecoturismo. Diferem, porém, de outros parques tradicionais pela sua conformação, capazes de congregar e dispersar pessoas, integrando diferentes áreas, paisagens, bairros e comunidades da cidade. Assim os Corredores Verdes apresentam vantagens sobre os demais parques, pois devido a sua linearidade, podem percorrer mais áreas do perímetro urbano e, portanto garantir mais acessibilidade e visibilidade pública.

Os Corredores Verdes contribuem para o Sistema de Parques da cidade de Raleigh, acomodando sete das 16 atividades previstas, como caminhada de lazer, ciclismo, piquenique, pesca, caminhada e observação paisagem junto a natureza, passeio a cavalo e escalada; também atividades como corrida, pesca e canoagem podem ocorrer nos Corredores Verdes (FLOURNOY, 1969). 


\section{Multifuncionalidades do Sistema de Corredores Verdes}

Flourney (1969) e Zachary et al. (1977), dentre os principais objetivos do Sistema de Corredores Verdes da Capital Area de Raleigh, mencionam:

- promover a estratégica de corredores como forma a minimizar os problemas de alagamentos e propiciar fluidez da drenagem pluvial como um sistema funcional e permeável;

- incorporar o sistema de infraestrutura verde e infraestrutura azul pela drenagem e permeabilidade hídrica, bem como conservação e manutenção da vegetação na cidade;

- promover o desenvolvimento estrutural de facilidades urbanas, principalmente no que tange ao esgoto doméstico (conduzido para as estações de tratamento) e drenagem pluvial (conduzido para as áreas de sistema natural com menos poluentes e vazão);

- introduzir um sistema efetivo para controlar o crescimento urbano, principalmente sobre as áreas naturais;

- preservar os atributos naturais de forma a promover a perpetuidade das funções ecológicas e paisagísticas;

- preservar a vida silvestre nas áreas urbanas;

- minimizar os conflitos urbanos e conflitos entre diferentes áreas e usos;

- complementar e conectar a cidade com outros parques;

- controlar a erosão do solo;

- reduzir poluição ambiental e promover a qualidade atmosférica e microclima urbano;

- minimizar poluição sonora;

- controlar o crescimento e pressão urbana sobre áreas conservadas de espaços livres;

- proporcionar próximo do perímetro de corredores verdes, usos urbanos mais compatíveis;

- valorizar economicamente as propriedades lindeiras aos corredores verdes;

- adicionar ao sistema de espaços livres, um sistema dinâmico e integrado de facilidades recreativas e paisagísticas;

- prover aos cidadãos de Raleigh oportunidades recreacionais junto as áreas naturais;

- promover a educação ambiental dos cidadãos, principalmente através das escolas, pelo contato com flora e fauna, a preservar e relacionar com a natureza;

- promover o incentivo de pesquisas e estudos científicos;

- promover a mobilidade urbana alternativa fomentando o aumento de rotas alternativas mais seguras e saudáveis aos pedestres e ciclistas, ligando áreas residenciais, comunidades, escolas, parques, zonas comerciais e serviço; 
- potencializar a vitalidade e perpetuidade do ambiente urbano,

- promover a integração social através de usos múltiplos sobre as áreas públicas.

\section{Elementos Projetuais Estruturadores dos Corredores Verdes}

Secundo Flournoy (1969), os elementos projetuais utilizados no planejamento e projeto dos Corredores Verdes da Capital Area de Raleigh são representados pelos seguintes aspectos:

laços: onde se podem encontrar dois tamanhos de configurações: maiores e menores; os laços maiores conformam um circuito representado pelas conectividades das áreas de Crabtree e Walnut Creek, formando um laço. As distâncias desses laços variam de 25 milhas, 40 milhas e 75 milhas. As trilhas dessa porção maior que ligam diferentes áreas comunitárias da cidade, por estarem circunscritas a esse, devem receber constantemente um intenso uso de pedestres e ciclistas e, portanto, devem ser planejadas para esses propósitos. Os laços menores consistem em corredores verdes caracterizados por padrões recreacionais, cujo objetivo principal esta na promoção de um corredor verde contínuo através do sistema circular, onde atividades recreacionais podem ocorrer;

penetradores: esse tipo de conformação de corredores verdes acaba conformando uma teia interconectada, representada pelos principais tributários da cidade: Cabtree e Walnut Creeks. O objetivo principal dos penetradores está em percorrer e alcançar todas as áreas urbanas da cidade, alcançando assim todas as suas partes, como forma a igualar os benefícios dos corredores verdes entre toda a população. As trilhas são caracterizadas pelas unidades de vizinhança, que constituem em características especificas de cada local. Estas servem como conectoras locais para o sistema de laços maiores.

\section{SITUAÇÃO ATUAL DAS ÁREAS DE RECREAÇÃO E LAZER: SISTEMA DE PARQUES E REDE DE CORREDORES VERDES}

Em 2004, o Departamento de Parques e Recreação de Raleigh complementou o Plano de Parques, com o intuito de consolidar bases sólidas ao Plano da Capital Area de Corredores Verdes e de projetar para o futuro as seguintes metas: facilitar acesso público as áreas naturais, incremento de programas, aumento e manutenção das facilidades e necessidades recreativas e revisão da legislação pertinente até 2030 (CITY OF RALEIGH PLANNING WEBSITE, 2010).

Conforme os dados censitários de Raleigh em 2019, apresenta 464.000 habitantes. Atualmente as áreas destinadas a Parques e Corredores Verdes, constituem um sistema configurado por 150 locais, com área extensiva de 8.800 acres (33 km²) e 3.300 acres, com 34 trilhas configuradas em 56 milhas $(89,6 \mathrm{Km})$ de corredores verdes, além de outras áreas destinadas a centros comunitários, áreas esportivas e praças (Figs. 5 e 6). 
Figura 5 - Mapa atual das Categorias Tipológicas de Raleigh e do Sistema de Parques e Corredores Verdes de Raleigh: Capital Area de Corredores Verdes.

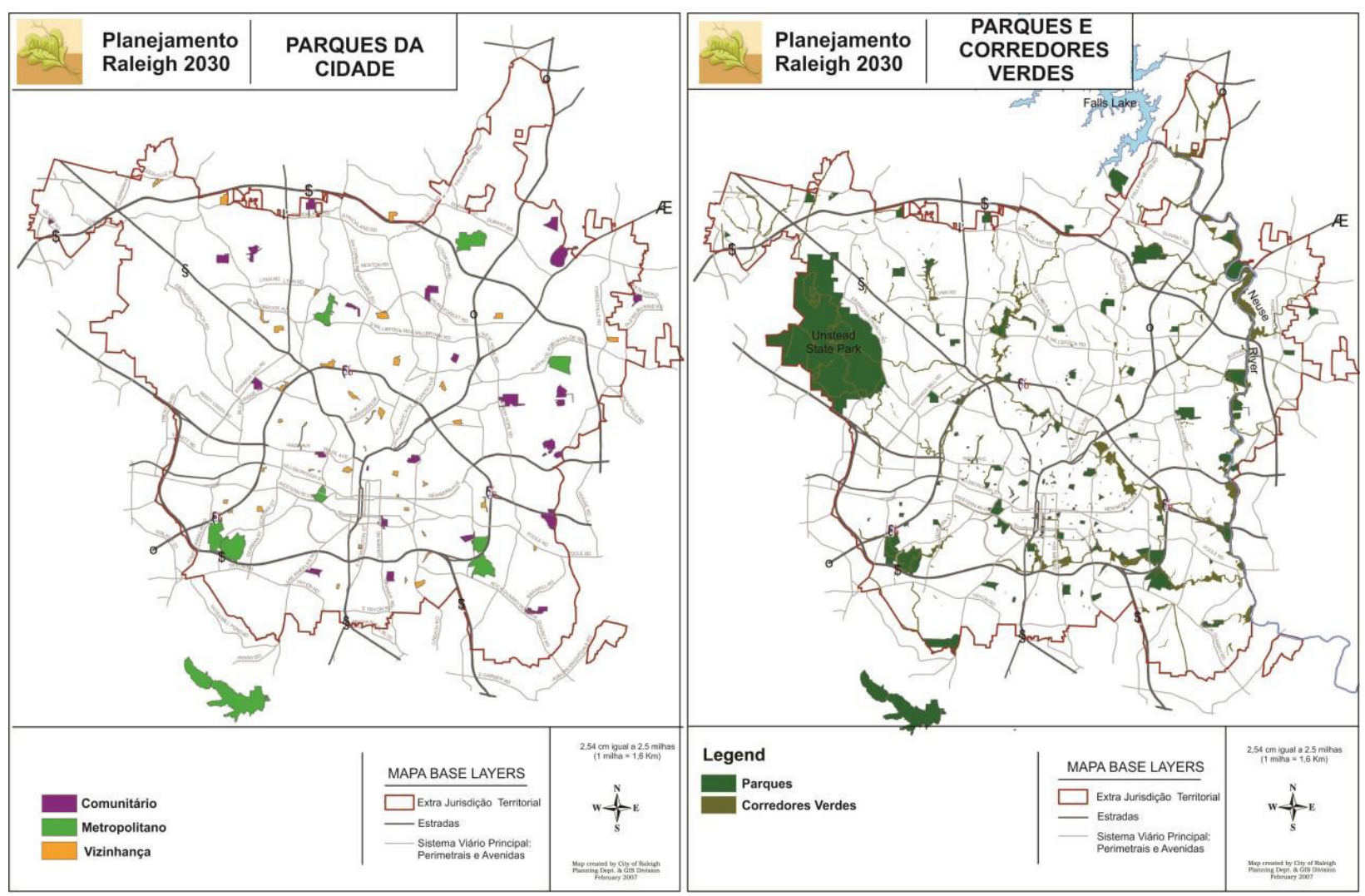

Fonte: modif. de CITY OF RALEIGH PLANNING WEBSITE, 2010.

Figura 6 - Ambiências dos parques e dos Corredores Verdes de Raleigh.



Fonte: L.G.A. Pippi, 2012. 


\section{RECOMENDAÇÕES FUTURAS PARA CAPITAL AREA DE RALEIGH: QUESTÕES E ESTRATÉGIAS POTENCIAIS}

Apesar do êxito do plano para a Capital Area de Raleigh: Parques e Corredores Verdes, ainda é preciso levar em consideração a continuidade do mesmo, de forma a incrementar ainda mais suas áreas naturais, seus atributos físicos, ambientais e paisagísticos com programas e atividades de lazer, recreação, práticas esportivas, educativas e turísticas. Também seria necessário incentivar o envolvimento e a participação do público para a eficácia do plano.

O Sistema de Lazer e Recreação de Raleigh, através de suas diversas categorias tipológicas de Parques e de sua Rede de Corredores Verdes, está projetado para atender suas necessidades até o ano de 2025, com a previsão de dobrar as áreas de parques e corredores verdes. Dessa forma, foram inventariadas e indicadas novas áreas de diferentes categorias de parques, bem como previsão para a interligação dos mesmos através de Corredores Verdes.

A qualidade de vida urbana de seus habitantes e funcionalidade de seu sistema, principalmente das áreas naturais, estaria garantida se forem planejadas e demandadas a aquisição de novas áreas, bem como oportunidades de ampliação e interligação da rede de corredores verdes, sem interrupções.

Ainda conforme Raleigh Parks and Recreation (2019), como principais estratégias em potenciais, estão as seguintes metas:

- buscar recursos financeiros para aquisição, projeto e implantação das novas áreas de parques e corredores verdes;

- promover o incremento da eficácia dos corredores verdes, através de sua renovação e incremento de suas facilidades, atributos físico-ambientais e paisagísticos, e estruturas físicas (construções, equipamentos, mobiliários urbanos e infraestrutura verde) e conservação de seus recursos;

- incrementar a implantação efetiva da infraestrutura verde de forma a beneficiar os objetivos do sistema de parques, áreas de recreação e corredores verdes, satisfazendo as necessidades da população e dos recursos naturais;

- rever e/ou prever metas de planejamento futuro a médio e longo prazo para as áreas de parques e recreação.

\section{CONSIDERAÇÕES FINAIS}

O planejamento e implantação da rede de corredores verdes na Capital Area mostraram ao longo dos anos o sucesso e benefícios desse programa percussor nos Estados Unidos, que promoveu não apenas uma cidade com um ambiente urbano mais sustentável, mas a perpetuação da implantação do Sistema de Parques e Corredores Verdes, com variadas funções no âmbito regional, nacional e internacional. O plano Raleigh: um Parque com 
uma cidade dentro serviu, portanto como um modelo a ser seguido por diversas cidades americanas e do exterior, devido a sua eficácia e êxito.

Atualmente, os Corredores Verdes são responsáveis pela manutenção e conservação de aspectos intrínsecos da paisagem de Raleigh, vitais para a potencialidade e viabilidade desse sistema integrado no âmbito local e regional. Tem sido bastante utilizado pela população local e turistas, durante o ano todo. Com relação à eficácia do Sistema de Parques Lineares, os Corredores Verdes de Raleigh têm sido mais procurados e utilizados do que os outros tipos de espaços livres da cidade devido as suas características, acessibilidade e visibilidade.

Para melhoria e benefício do sistema como um todo, é necessária a incorporação de novas áreas, o reordenamento da conectividade dos mesmos, sem interrupções pelo sistema viário, ao longo de um sistema contínuo de Corredores Verdes, bem como a interconexão de seus diferentes Parques em âmbito regional.

Finalmente, são necessários levantamentos atualizados quanto à frequência de uso e preferência dos usuários com relação aos aspectos característicos da paisagem e estrutura física dos parques, de forma a conduzir o planejamento, projetos, construção e requalificação dos Parques e Corredores Verdes tanto no presente, como no futuro.

\section{REFERÊNCIAS}

RALEIGH PARKS AND RECREATION. Capital Area Greenway System Map. Raleigh, 2019.

CITY OF RALEIGH PLANNING WEBSITE. Sistema Atual e Planejamento da Rede de Parques e Áreas Recreativas de Raleigh. Raleigh, 2010. Disponível em: <http://raleighcitizen.com/wp-content/ uploads/2012/02/Raleigh_NC_Greenway_System_Map.pdf> Acesso em: 02 out. 2019.

EVANS, Frank et al. Raleigh: The Park with a City in it. Raleigh: Park and Recreation Comission and Parks and Recreation Department / North Carolina State University, 1969.

FLINK, Charles; SEARNS, Robert M. Greenways: A Guide to Planning, Design, and Development. Washington, DC: Island Press, 1993.

FLOURNOY, William L. A Report to The City Concil on the Benefits, Potential and Methodology of Estabilishing a Greenway System in Raleigh. Raleigh: North Carolina State University, 1969.

LITTLE, Charles E. Greenways for America. Baltimore: The Johns Hopkins University Press, 1990.

ZACHARY, L.; CARPER, W.; BENTON JUNIOR, D. et al. The eighteen year parks and recreation plan for Raleigh 1977-1995: a part of the public services and facilities element of the comprehensive plan. Raleigh: The city of Raleigh Parks and Recreation Department/ The Comprehensive Planning Group and the city of Raleigh Planning Department, 1977.

Data de submissão: 10/ mar./ 2019

Data de aceite: 01/ out./ 2019 